\title{
Role-playing institutional academic integrity policy-making: using researched perspectives to develop pedagogy
}

\author{
Erika Löfström(1)
}

\author{
Correspondence: \\ erika.lofstrom@helsinki.fi \\ Centre for Research and \\ Development of Higher Education, \\ Institute of Behavioural Sciences, \\ University of Helsinki, \\ Siltavuorenpenger 5 A, P.O.Box 9, \\ Helsinki 00014, Finland
}

\begin{abstract}
This article describes research-based role-play on academic integrity. In the role-play, doctoral students negotiated the revision of an institutional integrity policy representing different groups of academics and students. On the one hand, role-play as a teaching method and learning activity demonstrated the difficulty of accommodating different perspectives; on the other, it showed the power and necessity of negotiation in matters that involve value judgments. The role-play is described in detail along with its underlying pedagogical foundations and its contextualisation in a doctoral summer school where it took place. The purpose of the article is to describe how academic integrity was approached through role-play and to discuss theoretical and pedagogical foundations of role-play in teaching academic integrity. Although the article does not describe empirical research on role-play as a teaching method, it demonstrates how role-play in teaching academic integrity was developed based on prior research on the topic.

Keywords: Academic integrity, Responsible conduct in research, Role-play, Doctoral education, Research-based teaching, University pedagogy
\end{abstract}

\section{Introduction}

The academic community around the world has shown increasing concern about university graduates' competence and integrity in the realm of research. Since the beginning of the twenty-first century, researchers have been investigating students' conceptions of integrity and related competences (e.g. Heitman et al., 2007; Bernardi et al., 2011; Emmerton et al. 2014), and student misconduct (e.g. Tryon, 2000; Chapman et al., 2004; Kremmer et al. 2007; Gynnild \& Gotschalk, 2008; Ison, 2012). Meanwhile, training initiatives have also been documented (e.g. Clarkeburn et al. 2002; Braunschweiger \& Goodman, 2007). For instance, using dilemmas or cases (O'Leary \& Cotter, 2000; Nonis \& Swift, 2001; McWilliams \& Nahavandi, 2006) and involving students in personal ethics action (Canary, 2007) have been shown to be successful teaching strategies. However, there is less documentation about role-play in teaching academic integrity. The aim of this article is 1) to describe a role-paly activity that is designed based on empirical research on academics' views of academic integrity, and 2) to reflect on role-play as a method for teaching academic integrity. The article does not report on a specific study nor does it provide empirical support for the use of role- 
play in teaching research ethics. However, none of the reviewed studies on role-play in the teaching of research ethics or academic integrity describes a role-play that is based on researched perspectives. The present description may be worthwhile in providing an example of how empirical research on academic integrity may inform teaching by roleplay as a method.

The purpose of the role-play described here was to demonstrate the complexity of academic integrity and the difficulties as well as the possibilities of fostering mutual understanding and commitment to integrity. Academic integrity is here understood as "logically coherent positions on ideal moral behavior, backed by actions that demonstrate this position, practiced by individuals or institutions in an education, research or scholarship setting" (Jordan, 2013, 252). In practice, the role-play encouraged the participants to think of a position on academic integrity and its boundaries with a predetermined role as the point of departure.

The role-play took place as part of a week-long international doctoral summer school. A stipulation of the summer school, which was devoted to research ethics and integrity, was to foster a positive perspective: Academic integrity is not only about dealing with misconduct, but also about doing the right thing and being proud of the fact that one lives up to highest moral standards in one's research work. The exercise allowed participants to experience a negotiation situation with the aim of finding a solution, namely designing an institutional academic integrity policy. In doing this, the participants were to explore and agree on what constitutes responsible conduct in research and breaches thereof.

\section{Role-play as a teaching method in higher education}

Role-play can be regarded as a teaching method/learning activity well aligned with notions of learner-centredness. According to current understanding of teaching and learning in higher education, learner-centred methods facilitate students' conceptual change (Martin et al., 2000; Kember \& Kwan, 2000). The concepts of role-play and simulation are used to describe teaching and learning which mimic real or realistic situations. While these two concepts are often used synonymously and are similar in practice in terms of student activity and engagement, distinctions have nevertheless been made. Role-play is primarily geared towards engaging students in recognising different perspectives. Simulations, in turn, help students to understand the dynamics of systems or processes (Wright-Maley, 2015). Both role-play and simulations are designed to represent reality-based problems or situations, but role-play typically involves less complex interactions among roles than do simulations (Wheeler, 2006). In the present study, both concepts, simulation and role-paly, were considered, but the decision was made to use the concept of role-play as the main focus was on learning through perspectivetaking. In this case the profiles, based on the results of a prior study, were more realistic than the negotiation process, which in reality would be longer and more complex, and would likely involve rounds of preparation work, hearing key stakeholders, and commenting draft proposals. In the present activity, this process contained such elements, but in a comprised form.

Role-play on academic integrity is hardly documented in the literature. In addition to literature on role-play on integrity, role-play on research ethics was also reviewed. Both 
domains may involve ethical and moral considerations, and therefore, it was thought that broadening the literature review to include also role-play on research ethics may add value to the review.

In teaching ethics-related content, role-play and simulations have been used, for instance, in education (Druckman \& Ebner, 2008; Shapira-Lishchinsky, 2013), nursing (Gropelli, 2010), business studies (Nelson et al. 2014), science and engineering (Wareham et al. 2006; Nadolny et al., 2013), law and social work (Druckman \& Ebner, 2008), history and political science (McCarthy and Anderson 2000), and international studies (Shaw, 2004). Wheeler (2006) presents an annotated review of thirty role-plays and simulations on international issues. Some of these (e.g. Tolley 1998) include components of business or other ethics. Furthermore, the use of games and cases may come close to role-play. Lloyd and Van de Poel (2008) describe the application of a game, Delta Design, to teach engineering ethics in design education. These authors conclude that the success of the game lies in connecting practical action with theoretical discussions. McWilliams and Nahavandi (2006) describe the use of live cases researched and further developed by students in the teaching of business ethics, and conclude that this method increases awareness of the complexities of ethics, enhances application of concepts, increases emotional engagement and students' personal accountability, and encourages critical thinking. Experimental designs comparing role-play and simulation with other forms of teaching have concluded that the role-play or simulation enhances classroom participation (McCarthy and Anderson 2000) and improves exam scores or grades (McCarthy and Anderson 2000; Frederking, 2005). The focus in these studies has been on professional ethics or field-specific ethical issues.

There are a few studies on role-play and simulations in teaching research ethics, research integrity or academic integrity, as well. Ralph Rosnow's (1990) study of roleplay evaluates the cost and benefits of research. Together with a validation study by Strohmetz and Skleder (1992), the work of these authors supports the notion that the teaching method is useful in raising students' awareness of the complexities of research ethics. The role-play in these studies involved identifying and critiquing "unethical" studies, taking the role of the author of such a study, and defending the study to a peer review board consisting of fellow students.

Rachel Kraus (2008) describes the use of student-generated plays on the violation of nine ethical norms in research. Based on overwhelmingly positive student feedback, Kraus concluded that the exercise was helpful, engaging and creative. Another study describes the application of the simulation method in compulsory undergraduate teaching of the scientific process (Gunnels et al., 2015). Students reviewed realistic funding applications and provided evaluations of the applications, ultimately assessing which projects were to "receive funding". The simulation was deemed successful because of the nature of the ethical issues that the students raised, and consequently, they were able to produce higher-quality research proposals themselves. Andrea M. Karkowski (2010) describes a simulated Institutional Review Board (IRB) exercise in which students reviewed mock research proposals in an effort to raise sensitivity to ethical issues and prepare students for scientific work. Similarly, a mock IRB simulation with students of sociology was found to generate in-depth discussion of ethical issues in research in sociology (Sweet, 1999). 
In what they call a simulation role-play, Druckman and Ebner (2008) have investigated the effectiveness of various tasks within the exercise. The results of their study showed that students who designed the scenarios benefitted the most in terms of concept learning and retention. While teachers typically design the role-play or simulation or use readily available products, the results of Druckman and Ebner (2008) encourage teachers to consider assigning designer roles to students. However, in the context of research ethics, in devising the role-plays students may tend to exaggerate ethical situations at the expense of dealing with content that is less obvious yet equally relevant (e.g. a grey area of questionable practices) (Kraus, 2008). Facilitators may assign such scenarios to students to make sure that a variety of ethical dilemmas are sufficiently covered.

To conclude, less evidence is available specifically on role-play and simulations in teaching research ethics and integrity, and academic integrity than on teaching professional or subject-specific ethics and ethical conduct.

\section{Context}

The role-play described here took place during the Fifth League of European Research Universities (LERU) Doctoral Summer School at the University of Helsinki in 2014. The theme of the summer school was "Doing the Right Things Right"-Research Integrity in a Complex Society. Forty-three students, mainly from LERU institutions, participated in the summer school. The group was multidisciplinary with participants representing social and behavioural sciences, the humanities, medical and life sciences, natural sciences, law, business and engineering.

The learning objectives of the summer school were the following:

1. to make available to doctoral students state-of-the-art research ethics and integrity through interaction with leading experts;

2. to raise awareness of and interest in ethical/integrity questions by creating a stimulating cross-disciplinary environment; '

3. to promote the students' appreciation for ethically sustainable solutions;

4. to support the students in developing tools for recognising, analysing and solving ethical/integrity dilemmas; and

5. to promote the development of such qualities and competences that prepare students to function as future ethical leaders in their research communities.

The role-play was intended to serve all objectives with 2 to 5 in particular, and it made use of the outcomes of Objective 1. Summer school topics included the ethical underpinnings of research, research integrity and academic integrity from a European perspective, field-specific ethical issues, the researcher in society, interacting with the media and ethical decision-making in research. Thirteen experts on research ethics and integrity highlighted these topics from a variety of perspectives during the week, including the perspectives of research financing and society, institutional leaders, journal editors, ethical review boards and researchers. Thus, during the week the participants were being prepared for multi-perspective thinking, which was also intended to support them in adopting specific perspectives in the role-play. The participants received a 
certificate for taking part in the summer school; however, exercises, including the roleplay, were not graded.

\section{The role-play: Negotiating an institutional integrity policy}

The aim of the role-play was to integrate the various perspectives on academic integrity presented during the summer school, and demonstrate their relevance for academia. While the summer school addressed both research ethics and integrity, the role-play was focused on responsible conduct in research, code of conduct and its breaches. The outcome of the role-play was an academic integrity policy that would sufficiently accommodate the views of different groups in academia so that all would feel that they could make a commitment to the mutual integrity policy. To bring out multiple perspectives on and approaches to academic integrity, the students were divided into five groups. Each group was to adopt a distinct perspective. The five perspectives emanated from prior research indicating that academics tend to hold views along distinct lines (Löfström et al., 2015). The profiles identified in that study formed the basis for the group types and group descriptions provided the students. All groups received a description, and each group had $3 \mathrm{~h}$ in mid-course (i.e. end of the third course day) to develop the perspective provided them. The groups were prompted to think of arguments in support of their view. The 43 students were divided into five groups. The five groups and their particular perspectives could be described as follows:

Group 1: Members of the institution's Ethical Review Board: “The academic integrity of our academic staff and students is substantially our responsibility, and we must teach both the rules and the values of academic integrity. We make sure our students learn these important things, as they are the future academics and researchers."

Group 2: University Teachers: "We think of ourselves as gatekeepers of the professions and of academia. If students do what we do, they will be fine and stay on the right track. Our task as role models is crucial!"

Group 3: Doctoral Students: "Universities should foster future generations of academics and citizens. Teachers: Challenge us, but pay attention to us as individuals!"

Group 4: Research Directors and Research Team Leaders: "We fly the flag for academic freedom and individual choice. Students must take responsibility for their own behaviour. We are not parents or babysitters!"

Group 5: Administrative Research Secretaries: "Teachers must make sure that the students know the rules. It is what they do that counts! If the students know the rules, they will be fine, and they will manage to find their way through the academic system."

In reality, not all students, teachers, research directors and so on will have the same views, but for the sake of keeping the task manageable, one group of students was to adopt one academic role and one perspective. These roles were based on a prior study exploring academics' conceptions of their roles in promoting academic integrity in a supervisory context. The study utilised Q-methodology and 
was carried out in two universities in different regions of the world (Löfström et al., 2015). Q-methodology is a quali-quantological approach suitable for studying complex phenomena about which different points of view can be expressed (Brown, 1996). Instead of responding to a set of items, the participant scrutinizes the items from a self-referential point of view and ranks the items in relation to each other and based on what he or she believes to be true from his/her perspective. The outcome of the research is a set-up of items expressing different values that are helpful in understanding how individuals position themselves on matters in which values play a crucial role. Individuals may respond to items in the same way, but for completely different reasons. Through the ranking process, the Qmethod affords a general overview of relevant viewpoints on the matter in question (Watts \& Stenner, 2005; Stenner et al. 2008). Designing the statements is a very important step in the process, and these should represent a broad array of possible views on the topic. For this purpose, a thorough literature review is necessary. Participants rank the items in a grid providing a numeric value to each item (based on the extent to which the participant agrees or disagrees with or feels neutral about the item). The "sorts" are then analysed with a factor analytical procedure, in which items are viewed as cases and participants as variables. The notion of representative sampling, thus, applies to items in the $\mathrm{Q}$ set, not the participants, as in conventional factor analysis (Stenner et al. 2008).

In the study, based on which the role-play profiles were created, participants sorted 42 statements into a pre-determined grid with an 11-point scale from -5 to 0 to +5 . The results suggested that academics in the two studied contexts may be divided into five groups on the basis of qualitatively different views on academic integrity, including (1) how best to teach academic integrity, (2) whose responsibility it is to teach it, (3) what is the most appropriate source of moral and ethical guidance, (4) the need for academic development of integrity, (5) student collaboration versus collusion, and (6) the role of whistle-blowing. It appeared that, despite well-developed integrity infrastructures and policies, academics do not have consensus on some basic aspects of integrity. The diversity of opinion is likely to have an impact on the efficacy of institutional academic integrity policy implementation (Shephard et al., 2015). Therefore, the five profiles were deemed suitable for a role-play to negotiate an institutional academic integrity policy.

Along with their group profile, the groups received the following task description:

"At our university there have been some breaches in integrity recently. Many colleagues have been concerned about the current state of affairs-Where is our university headed? The Rector of the University calls a meeting in order to find out what people at the university think about the situation.

"It is evident that the integrity policy of the university is not working and should be revised. But how? There are two things we should focus on: 1) How to react to cases of misconduct, and 2) How to proactively facilitate high levels of integrity so that breaches are not repeated in the future. The first point means that we should think about what would be the right procedure for dealing with misconduct. Who should 
be responsible, and for what, in that process? The second point means that we must focus on educating staff and students. We are particularly keen on developing integrity and ethics education for our students as this is our pool of future scientists and academics. But again, whose responsibility is it to teach integrity?

"In order to prepare for the Rector's meeting, we ask you to think about these questions in your group:

1. Whose job is it to teach integrity? What is the best way to teach integrity/How do students learn about it? Can integrity be promoted in other ways in addition to teaching it?

2. What kind of process for dealing with misconduct should be in place? What is the purpose of this process? Why should there be a protocol and a process in place?"

The role-play included the following steps:

Day 1 (time: $3 \mathrm{~h}$ )

1. Division into groups and familiarization with the task.

2. Familiarisation with the descriptions of group perspectives and adoption of assigned group perspective through discussion of how the group would react to a set of specific questions given their adopted perspective.

3. Choosing spokespersons for the groups.

4. Choosing the group's chair/rector and secretary

Day 2 (time: $3 \mathrm{~h}$ )

5. Revisiting the group perspective in groups and refreshing the views and arguments.

6. First panel discussion with the spokespersons explicating the groups' policy priorities, led by the rector and facilitated by the secretary.

7. Group work to revisit policy priorities.

8. Second panel discussion with the spokespersons explicating revised policy priorities.

9. "Temperature check" by the rector to establish the level of consensus.

10.Termination of exercise (Option: to continue until sufficient consensus on a mutual policy is reached).

11.Debriefing, i.e. reflection on a) the process of negotiating a mutual policy, and b) each participant's learning experience, including perspective-taking as a method to develop one's understanding of academic integrity.

A key element of the role-play was staged as a panel discussion with representatives from each group on the panel. The panel's task was to give their group's view on an integrity policy to the rector of the university and debate the views presented by others. One student volunteered to act as rector and chair the role-play. Another student volunteered to take the role of secretary at the rector's office and be in charge of writing up a policy based on a panel discussion conveying the views of the five groups. These two students did not participate in the group discussions at the beginning to avoid bias towards a specific group. Instead, they familiarised themselves with the five group profiles in order to be adequately prepared for their task. Each of the five groups chose a spokesperson who would participate in the panel discussion in order to convey 
the group's position on academic integrity policy to the rector. For the student who acted the part of the rector, it was important to listen to all groups of academics with the goal of establishing a policy statement to which everyone could commit. Therefore, each group's panel member was a spokesperson who had an important role in conveying the group's take on integrity, the handling of misconduct and advancing integrity.

The morning of the last day of the summer school was dedicated to the panel discussion and debate. The goal of the panel discussion was to hear out how each group positioned itself with regard to academic integrity and come to a mutual agreement about a basic policy description regarding the responsibilities for integrity and the handling of misconduct. All groups had prepared arguments to support their views. The spokespersons on the panel had prepared a short talk to present their group's position. The discussion was lively, and as expected, it became evident that achieving consensus was difficult.

During the panel discussion, the groups had the opportunity to support their spokesperson or voice their opinions through interactive technology (Smartboards and iPads). The groups assembled as the audience, but their role was not to observe the panel discussion passively. Instead, the groups were equipped with iPads, and their comments, objections and approving remarks were reflected in real-time on a white board. Through interactive technology everyone had the opportunity to comment on the draft policy as it was being written up. A technical facilitator organised the messages according to the groups that presented them (with the help of colour coding of the messages). Without the support of the technical facilitator it may have been difficult for the spokespersons and the audience to quickly get an overview of each group's concerns. With the instant thematic sorting the spokespersons were able to quickly pick up arguments from their group and they also used this opportunity.

The rector's task was to coordinate the discussion and determine whether the policy statement could be written to reflect the views of all groups. This was important in order to facilitate all stakeholders' commitment to the policy. The secretary recorded key points from each spokesperson's speech and drafted the policy.

After each of the panel spokespersons had heard one another's perspectives, they discussed the draft. If the spokespersons hit a dead and not being able to agree on a draft policy satisfactory to every group, the rector was instructed to send the spokespersons back to their core groups to revisit their policy priorities and seek a solution for negotiating further on the policy statement. Thus, the group was to decide which priorities they could give up or compromise on and based on what arguments and which priorities they would not be willing to compromise on.

The rector used this opportunity to send panellists back to their core groups. After a brief group session the spokespersons returned to the panel to present their revised solutions. The secretary edited the draft policy as the discussion unfolded. The edited texts were projected on the white board for all to see and follow. When all spokespersons had presented their solutions, there was another round of discussion led by the rector, who then took a "temperature check" of the whole group, asking if the groups felt that they were any closer to a statement that would satisfy all views.

At this point the course leader/facilitator had the option of continuing or ending the exercise. In this case the role-play was terminated with four groups having reached consensus on the academic integrity policy and one group dissatisfied with the outcome, which they felt did not support their work. 
The next step was a debriefing, the aim being to reflect on the process of negotiating a mutual policy. The students were encouraged to compare their group view with their own views and reflect on whether taking another perspective had influenced their understanding. The debriefing served the purpose of closure for the exercise despite the fact that no definite solution was reached during the role-play itself. The debriefing also provided an opportunity to discuss what can be learned through perspective-taking and to reflect on the importance of being aware of priorities other than one's own. The students actively discussed their experience, and many of them voiced the differences between their own and role views indicating that taking on another perspective indeed facilitated reflection.

The exercise lasted approximately $6 \mathrm{~h}$ spread over 2 days. It is possible to complete the exercise in 1 day if required by the overall schedule, or alternatively allocate more time for preparation or the panel activity. However, according to Wedig (2010), the best ratio for preparing and carrying out a simulation is one to one. This ratio worked well in the present role-play. Even if the time available was relatively short, by working in a succinct and focused way the participants maintained interest and motivation; with only limited time, they were strongly geared to search for a solution (cf. also Wedig, 2010). This helped to keep up momentum and maintain focus.

\section{Pedagogical underpinnings}

The role-play took as its point of departure a realistic case (cf. also Gunnels et al., 2015) of a university that is about to revise its academic integrity policy owing to recent events prompting a scrutiny of policies and procedures. This scenario was contextualised in a university setting, which, as a context, is familiar to doctoral students. Also the sessions earlier in the week served the purpose of grounding integrity in the core activities of academia, i.e. publishing, applying for financing and communicating research to the wider society, for instance, through the media. The exercise was active and student-led, facilitated perspective-taking, allowed for a variety of roles to be adopted and applied interactive technology to facilitate engagement. The role-play included whole group settings, a panel discussion and work in small teams. Using teams adds a layer of internal negotiation to the exercise, which may facilitate the development of students' collaboration competences (Wedig, 2010). While individual roles may create stronger accountability demands on individual students, team roles are more viable in fairly large groups, such as the present one.

A debriefing/reflection session took place after the role-play. Students were prompted to reflect on their own viewpoints relative to the perspective they had adopted for the role-play. While the teacher/facilitator planned the role-play, the exercise itself was student-led, that is, the facilitator gave up control over the direction and outcome of the task, which is common for simulations that allow students much space to develop their role and the outcomes in various directions (cf. Wedig, 2010). The only restraint was the initial role description, which provided a starting point for negotiating the institutional policy. The groups, of course, needed to stay true to the value basis in the description. Within those parameters, the space was open, and there was no particular outcome to be achieved, as is often the case (for instance, in historical role-play). 
The facilitator's role is to "set the stage" for learning to take place. This requires careful thought on the constructive alignment of intended learning outcomes, content and method, as well as interaction between students (cf. Biggs 1999; Biggs \& Tang, 2007). The view underpinning the teaching was that of facilitation, with learning as agency. Once the elements of the learning process were planned, the facilitator handed over the task to the students, who took responsibility for their learning. Giving up control of the situation may be alien to teachers who are used to being in charge and in control of learning situations. However, student-driven exercises are effective in simulations (Wedig, 2010), and this idea was applied in the current role-play. The role of the facilitator was to design a role-play that would help achieve specific learning goals, to monitor the role-play during the process to ensure that it unfolded constructively and to provide encouragement to the students (cf. Wedig, 2010). The removal of the teacher's leadership role together with dilemmas without clearly solvable outcomes introduces dynamism into the exercise (Wright-Maley, 2015).

The summer school venue boasted an Engaging Learning Environment with interactive learning technologies, including Smartboards for group work and iPads for realtime interaction. This technology has the advantage of engaging large groups and provides a space for all to participate. This may be particularly helpful for individuals who do not feel comfortable speaking up in a large group. It also allowed participants to raise and make alternative viewpoints visible. The technology served the purpose of the exercise well in demonstrating the multi-perspective nature of the topic (i.e. giving visibility to alternative views) and helped to involve a majority of learners in active roles (cf. also Wright-Maley, 2015).

Designing simulations or role-play is time consuming, and requires pilot-testing in order to make sure that the exercise holds together in a classroom situation (Wedig, 2010). In this case, there was confidence in the basic idea of the five roles and their sustainability in a classroom situation, as these roles were research-based. They had emerged in a prior study on academics' conceptions about academic integrity and their roles and responsibilities in promoting it. The fact that these roles were empirically underpinned was likely to boost the sense of realism in the role-play. In addition to appropriate content, the orchestration of the exercise and the manner of providing a suitable level of instruction are important. To test the appropriate level of instruction and the overall functionality of the scheme, two role-playing pilot sessions were performed with groups of approximately 20 participants who were academics involved in university pedagogical training. In both pilot sessions the participants were collaborative in taking on and engaging in the roles, which provided assurance that the concept is sufficiently well developed. The pilot sessions also showed that it was difficult for some participants to take on a role that was in conflict with their personally-held views. Therefore, in the summer school substantially more time was reserved for the groups to discuss and to get "inside" their role. While the role-play took approximately $6 \mathrm{~h}$, the pilot tests took about $2 \mathrm{~h}$. Nevertheless, they were important for testing the overall concept and instructions.

\section{Transfer of learning}

In role-play such as the one described here, it can be fully acceptable for the groups not to reach agreement. Any kind of outcome may be possible, and indeed, 
is acceptable. The outcome, which in this case was a draft policy document, is not the only outcome of the role-play. Process outcomes (cf. Biggs \& Tang, 2007) included the adoption of an alternative perspective and engagement in negotiation. A possible next step could be for students to compare the academic integrity policy that they have created with the policy of their own institution, and analyse what the challenges might be in implementing their actual institutional policy and how that policy might be developed to increase the staff's and the students' commitment to it. Thus, a further learning outcome could be to get a deeper understanding of the policies that guide academics in one's own institution and to view own practices and the practices of one's research community against the institutional policy with the aim to foster a culture of integrity.

The role-play triggered follow-up action: the summer school participants generated a fully student-led initiative on developing a doctoral students' statement on integrity, which was circulated among key stakeholders in the LERU community approximately 2 months after the summer school. A group of students continued working on the statement after the summer school, and social media was harnessed to allow all summer school participants to contribute with feedback and ideas. This suggests that the role-play had raised the student' awareness of their opportunities to influence integrity matters in academia. A concern with all learning is its transferability, i.e. its application to novel or different contexts. One problem is often that the knowledge gained does not automatically transfer to another context. The students' initiative in devising a doctoral student statement suggests that a transfer took place from the course context to the students' real institutional contexts. Furthermore, similar to other researchers (i.e. Gunnels et al., 2015; McCarthy \& Anderson, 2000), this activity suggests that there is applicability of the exercise irrespective of the students' disciplinary background. However, the participants in the role-play were doctoral students, and thus represented an advanced group of individuals. It is perhaps for that reason that the participants were able to utilise what they learned in a subsequent extra-curricular activity. They also had sufficient experience in academia to have been exposed to some of the roles of professors, institutional review board members and administrators. The activity may not work equally well with students who have less exposure to various academic roles.

Feedback ${ }^{1}$ was collected to provide an indication of how the participants experienced the summer school with its different exercises and what kind of investment they made during it in their own learning. The participants rated their overall satisfaction with the summer school as 4 (on a scale from 1 to 5 where $1=$ very unsatisfied, $5=$ very satisfied). They also rated their own engagement with the topic of the summer school and the learning activities as 4 (on a scale from 1 to 5 where $1=$ no active engagement, $5=$ very active engagement). While the summer school hosted a variety of activities, the role-play was among those providing the most opportunity for active participation, and the participants appear to have taken advantage of this task. As one of the participants expressed it in the open feedback, "exercises where you look at things from different perspectives were very useful. They make you question you assumptions!” Students suggested that the role-play might have been better placed at the beginning of the summer school in order to promote the participants' learning processes and lead 
to a concrete outcome within the summer school time frame. However, when placed at the middle (the preparation) and end (the panel) of the program, the participants were able to utilise content from the summer school sessions to inform their group profile.

Summer school objectives 2, 3 and 5 were achieved well. The role-play was intended to support awareness of and interest in ethical/integrity questions by creating a stimulating cross-disciplinary environment (mean 3.7 on a scale from 1 to 5 where 1 = very poorly achieved, $5=$ very well achieved), support appreciation for ethically sustainable solutions (mean 3.8), and to promote the development of such qualities and competences that prepare students to function as future ethical leaders in their research communities (mean 3.6). The fourth goal related to developing tools for recognising, analysing and solving ethical/integrity dilemmas was reached to a lesser extent (mean 3.1). While observations spoke for the transference of competences (e.g. the student-led initiative developing a doctoral students' statement on integrity) further discussion might have been beneficial in helping participants to conceptualise the "tools" that they were already applying.

\section{Conclusion}

This article described a role-play on academic integrity, in which doctoral students negotiated the revision of an institutional integrity policy taking on different stakeholder roles. The role-play activity utilised researched perspectives in an attempt to facilitate perspective-taking and broadening views of some of the complexities involved in creating a culture of integrity. A role-play, such as this one, serves the purpose of raising awareness of various policies guiding responsible conduct in research (i.e. international, national and institutional policies), which is an important step towards increasing commitment to high ethical standards. The article suggests a model for applying role-play to teach academic integrity in doctoral education. The added value is that it describes the design and implementation of a research-based exercise in which the roles were based on a prior study exploring academics' conceptions of their responsibilities in promoting academic integrity. In order to establish evidence for the utility of role-plays as teaching method, empirical research, for instance with an experimental design, will be necessary.

\section{Endnotes}

${ }^{1}$ Thirty-eight participants provided anonymous feedback. They were asked to tick a box if they allowed their feedback to be used for research and reporting purposes. All participants consented. Such a study would not require ethics review in Finland as it did not involve intervention in the physical integrity of research participants; deviate from the principle of informed consent, involve participants under the age of 15 being studied without parental consent; expose participants to exceptionally strong stimuli; cause long-term mental harm beyond the risks encountered in normal life; or signify a security risk to subjects (Finnish Advisory Board on Research Integrity 2009). 
Competing interest

The author declares that she has no competing interests..

Received: 26 August 2016 Accepted: 15 November 2016 Published online: 22 November 2016

\section{References}

Bernardi RA, Lecca CL, Murphy JC, Sturgis EM (2011) Does education influence ethical decisions? J Acad Ethics 9(3): 235-256

Biggs J (1999) What the student does: Teaching for enhanced learning. High Educ Res Dev 18(1):57-75

Biggs J, Tang K (2007) Teaching for quality learning at university, 3rd edn. Society for Research into Higher Education \& Open University, Maidenhead

Braunschweiger P, Goodman KW (2007) The CITI program: An international online resource for education in human subjects protection and the responsible conduct of research. Acad Med 82(9):861-864

Brown SR (1996) Q methodology and qualitative research. Qual Health Res 6(4):561-567

Canary HE (2007) Teaching ethics in communication courses: An investigation of instructional methods, course foci, and student outcomes. Commun Educ 56(2):193-208

Chapman KJ, Davis R, Toy D, Wright L (2004) Academic integrity in the business school environment: I'll get by with a little help from my friend. J Marketing Educ 26(3):236-249

Clarkeburn H, Downie JR, Matthew B (2002) Impact of an ethics programme in a life sciences curriculum. Teach High Educ 7(1):65-79

Druckman D, Ebner N (2008) Onstage or behind the scenes? Relative learning benefits of simulation role-play and design. Simulat Gaming 39(4):465-497

Emmerton L, Jiang H, McKauge L (2014) Pharmacy students' interpretation of academic integrity. Am J Pharm Educ 78(6):119

Finnish Advisory Board on Research Integrity (2009). Ethical principles of research in the humanities and social and behavioural sciences and proposals for ethical review. Helsinki. Retrieved from http://www.tenk.fi/sites/tenk.fi/files/ ethicalprinciples.pdf Oct 29, 2016.

Frederking B (2005) Simulations and student learning. J Polit Sci Educ 1(3):385-393

Gropelli TM (2010) Using active simulation to enhance learning of nursing ethics. J Contin Educ Nurs 41(3):104-105

Gunnels CW IV, Bovard BD, Buzasi D, Cassani MK, Douglass J, Everham EM III, Hartley A, Herman J, Mujtaba M, Muller J, Nelson K, Nicolas A, Southard L, Thomas S, Demers NE (2015) Engaging students in ethical considerations of the scientific process using a simulated funding panel. CURQ 26(1):12-18

Gynnild V, Gotschalk P (2008) Promoting academic integrity at a Midwestern University: Critical review and current challenges. IJEI 4(2):41-59

Heitman E, Olsen C, Anestidou L, Bulger RE (2007) New graduate students' baseline knowledge of the responsible conduct of research. Acad Med 82(9):838-845

Ison D (2012) Plagiarism among dissertations: Prevalence at online institutions. J Acad Ethics 10(3):227-236

Jordan SR (2013) Conceptual clarification and the task of improving research on academic ethics. J Acad Ethics $11: 243-256$

Karkowski AM (2010) Activities to help students appreciate committees that protect research participants. CURQ 30(3):11-14

Kember D, Kwan KP (2000) Lecturers' approaches to teaching and their relationship to conceptions of good teaching. Instr Sci 28(5):469-490

Kraus R (2008) You must participate. Violating research ethical principles through role-play. College Teach 56(3):131-136

Kremmer ML, Brimble M, Stevenson-Clarke P (2007) Investigating the probability of student cheating: The relevance of student characteristics, assessment items, perceptions of prevalence and history of engagement. IJEI 3(2):3-17

Lloyd P, Van de Poel I (2008) Designing games to teach ethics. Sci Eng Ethics 14(3):433-447

Löfström E, Trotman T, Furnari M, Shephard K (2015) Who teaches academic integrity and how do they do it? High Educ 69(3):435-448

Martin E, Prosser M, Trigwell K, Ramsden P, Benjamin J (2000) What university teachers teach and how they teach it. Instr Sci 28:387-412

McCarthy JP, Anderson L (2000) Active learning techniques versus traditional teaching styles: two experiments from history and political science. Innovat High Educ 24(4):279-294

McWilliams V, Nahavandi A (2006) Using live cases to teach ethics. J Bus Ethics 67(4):421-433

Nadolny L, Woolfrey J, Pierlott M, Kahn S (2013) SciEthics Interactive: science and ethics learning in a virtual environment. Etr\&D-Educ Tech Res 61(6):979-999

Nelson J, Smith LB, Hunt CS (2014) The migration toward ethical decision making as a core course into the b-school: instructional strategies and approaches for consideration. J Educ Bus 89(1):49-56

Nonis S, Swift CO (2001) An examination of the relationship between academic dishonesty and workplace dishonesty: a multicampus investigation. J Educ Bus 77(2):69-77

O'Leary C, Cotter D (2000) The ethics of final year accountancy students: an international comparison. Manag Audit J 15(3):108-115

Rosnow RL (1990) Teaching research ethics through role-play and discussion. Teach Psychol 17:179-181

Shapira-Lishchinsky O (2013) Team-based simulations: learning ethical conduct in teacher trainee programs. Teach Teach Educ 33:1-12

Shaw CM (2004) Using role-play scenarios in the IR classroom: An examination of exercises on peacekeeping operations and foreign policy decision making. ISP 5(1):1-22

Shephard K, Trotman T, Furnari M, Löfström E (2015). Teaching research integrity in higher education: policy and strategy. J High Educ Policy Manag DOl: 10.1080/1360080X.2015.1102823

Stenner P, Watts S, Worrell M (2008) Q Methodology. In: Willig C, Rogers WS (eds) Sage handbook of qualitative research methods in psychology. Sage, London, pp 215-239 
Strohmetz DB, Skleder AA (1992) The use of role-play in teaching research ethics: a validation study. Teach Psychol 19(2):106-108

Sweet S (1999) Using a mock institutional review board to teach ethics in sociological research. Teach Sociol 27(1):55-59

Tolley H (1998) Project THRO: Teaching human rights on-line. Hum Rights Quart 20(4):945-961

Tryon GS (2000) Ethical transgressions of school psychology graduate students: a critical incidents survey. Ethics Behav 10(3):271-279

Wareham DG, Elefsiniotis PT, Elms DG (2006) Introducing ethics using structured controversies. Eur J Eng Ethics 31(6): $651-660$

Watts S, Stenner P (2005) Doing Q methodology: Theory, method and interpretation. Qual Res Psychol 2:67-91

Wedig T (2010) Getting the most from classroom simulations: strategies for maximizing learning outcomes. Ps-Polit Sci Polit 43(3):547-555

Wheeler SM (2006) Role-playing games and simulations for international issues courses. J Polit Sci Educ 2(3):331-347

Wright-Maley C (2015) Beyond the "Babel problem": defining simulations for the social studies. JSSR 39(2):63-77

\section{Submit your manuscript to a SpringerOpen ${ }^{0}$ journal and benefit from:}

- Convenient online submission

- Rigorous peer review

- Immediate publication on acceptance

- Open access: articles freely available online

- High visibility within the field

- Retaining the copyright to your article

Submit your next manuscript at $>$ springeropen.com 